\title{
Neurogranin: Immunocytochemical Localization of a Brain-Specific Protein Kinase C Substrate
}

\author{
Alfonso Represa, ${ }^{1}$ Jean Christophe Deloulme, ${ }^{2}$ Monique Sensenbrenner, ${ }^{2}$ Yehezkel Ben-Ari, ${ }^{1}$ and Jacques \\ Baudier $^{2}$ \\ IINSERM Unite 29, 75014 Paris, and ${ }^{2}$ Centre de Neurochimie du CNRS, INSERM Unite 44, 67084 Strasbourg, France
}

\begin{abstract}
The developmental expression and the cellular localization of neurogranin (formerly designated p17), a brain-specific protein kinase $C$ (PKC) substrate, were investigated. The developmental expression of neurogranin was studied by immunoblotting of rat brain and neuronal cell-culture extracts using neurogranin polyclonal antibodies. Neurogranin synthesis was found to be developmentally regulated, with no expression in the embryonic and neonatal period and an abrupt increase between 2 and 3 weeks of age. By immunohistochemistry, neurogranin was found essentially in the adult rat telencephalon, specifically located in the cell bodies and dendritic processes of neurons of the cerebral cortex, hippocampus, striatum, and a few other discreet areas. Neurogranin immunoreactivity was nearly absent in the thalamus, cerebellum, and brain stem. The late developmental expression and the dendritic localization of neurogranin in neurons are 2 features that also characterize the type I PKC isozyme. The specific localization of the protein in integrative areas of the rat brain suggests a highly speciallzed function of neurogranin in the CNS. A possible role for neurogranin in the transduction of the PKC activation signals at the postsynaptic level is suggested.
\end{abstract}

Protein kinase C (PKC), a $\mathrm{Ca}^{2+}$-activated phospholipid-dependent kinase, is the receptor for tumor-promoting phorbol esters and is thought to play an important role in controlling several cellular processes (see Nishizuka, 1988, for review). PKC is present ubiquitously in a variety of tissues and is especially concentrated in the brain (Huang et al., 1986). Three different PKC isozymes, designated types I, II, and III, have been described (Huang et al., 1986). They are products of $\gamma-, \beta-$, and $\alpha$-type genes, respectively (Coussens et al., 1986; Brandt et al., 1987). In situ hybridization and direct immunohistochemical studies revealed differences in the distribution and developmental expression of the 3 PKC isozymes in the brain, suggesting that the different isozymes of PKC have distinct functions (Brandt et al., 1987; Huang et al., 1987; Hashimoto et al., 1988; Yoshida et al., 1988).

Received Apr. 2, 1990; revised June 14, 1990; accepted July 12, 1990.

We would like to thank Dr. T. Janet for his help in immunizing rabbits. We are also indebted to Miss Boudoin and Miss S. Guidasci for their technical and photographic assistance. We wish to thank Dr. K. Langley for carefully reading the manuscript. This work was supported by the French Association pour la Recherche sur le Cancer Grant ARC 6451 and by INSERM.

Correspondence should be addressed to Dr. J. Baudier, Centre de Neurochimie du CNRS, INSERM Unite 44, 5 Rue Blaise Pascal, 67084, Strasbourg, France J.C.D. is a recipient of a fellowship from the Association Française Contre les Myopathies.

Copyright @ 1990 Society for Neuroscience $0270-6474 / 90 / 123782-11 \$ 03.00 / 0$
An understanding of the exact function of the different PKC isozymes requires the identification and characterization of their in vivo substrates. In the brain, only $2 \mathrm{PKC}$ substrates have been formally identified and characterized: neuromodulin (also called GAP43, B50, F1, p57, and pp46; Alexander et al., 1988) and MARCKS protein (also called p87; Stumpo et al., 1989). Neuromodulin is a calmodulin-binding phosphoprotein of the presynaptic membrane that is associated with the initial establishment, regeneration, and functional modulation of synaptic relationships and appears to play a role in signal transduction mechanisms (Van Hoffet al., 1988). P87 is a protein of unknown function that has a widespread tissue and subcellular distribution (Albert et al., 1986).

We recently reported the purification of a new in vitro specific PKC substrate from the bovine brain, called p17 from its apparent molecular mass in SDS gel (Baudier et al., 1989). A straightforward purification method for $\mathrm{p} 17$ and neuromodulin was developed using the property of these PKC substrates of remaining soluble in 2.5\% perchloric acid (Baudier et al., 1989). The biochemical characterization of the $\mathrm{p} 17$ molecule has now been extended in our laboratory, and results will be published elsewhere. Significant structural and functional analogies between p17 and neuromodulin have been found. The purified p17 protein has a molecular mass of $7.8 \mathrm{kDa}$, as determined by ion-spray mass spectroscopy and protein sequencing, which is 2-fold lower than its apparent molecular mass on SDS gels (Cimler et al., 1987). P17 binds to calmodulin-Sepharose columns in the absence of calcium, a feature that also characterizes neuromodulin (Masure et al., 1986). Although the primary structurc of $\mathrm{p} 17$ is unique, a striking conserved amino acid sequence, AA(X)KIQASFRGH(X)(X)RKKL(X)K, was found between p17 and neuromodulin. This 18 -amino acid consensus sequence between bovine $\mathrm{p} 17$ and mammalian as well as fish neuromodulin represents the PKC phosphorylation site and the predicted calmodulin-binding domain, suggesting a possible evolutionary link between p17 and neuromodulin (LaBate and Skene, 1989; J. Baudier, J.C. Deloulme, H. Matthes, and M. Sensenbrenner, unpublished observations).

In the present study, we report the tissue distribution and expression of $\mathrm{p} 17$ in the rat brain. Because preliminary electron microscopic studies have shown that $\mathrm{p} 17$ is often found in granulelike structures in pyramidal cells of the hippocampus and cortex, we will hereafter refer to the $\mathrm{p} 17$ protein as neurogranin.

\section{Materials and Methods}

Purification of proteins. Bovine brain neurogranin (p17) was purified as previously described (Baudier et al., 1989). For rabbit immunization, a final purification step was included, consisting of reverse-phase chromatography on a Pro RPC column. Neurogranin was eluted at $0.5 \mathrm{ml} /$ 
min with a $50-\mathrm{ml}$ linear gradient of $0-50 \%$ acetonitril with $0.1 \%$ trifluoroacetic acid. Neurogranin eluted at about $20 \%$ acetonitril. The protein was then extensively dialyzed against $20 \mathrm{~mm}$ Tris- $\mathrm{HCl}(\mathrm{pH}, 7.5)$ plus $10 \mathrm{~mm}$ dithiothreitol (DTT) and $1 \mathrm{~mm}$ EDTA and stored at $-20^{\circ} \mathrm{C}$. Bovine brain neuromodulin and $\tau$ proteins were prepared as previously described (Baudier et al., 1987, 1989).

Production of antibodies. Antibodies against purified neurogranin, neuromodulin, and $\tau$ proteins were prepared in New Zealand white rabbits. The proteins $(300-500 \mu \mathrm{g})$ were emulsified in complete Freund's adjuvant and injected intradermally at multiple dorsal sites. At 2-3week intervals, the rabbits were given 2 other booster injections of 150 $250 \mu \mathrm{g}$ proteins in incomplete Freund's adjuvant. The rabbits were bled repeatedly, and the antibody titers were determined by Western blotting. Antisera that showed significant activity at 1:1000 dilution were collected. A second type of rabbit antiserum against neurogranin was obtained by injecting the neurogranin monomer, which was cut directly from the SDS-polyacrylamide $(0.1 \%: 12.5 \%)$ gels and emulsified in incomplete Freund's adjuvant. This antiserum gave similar immunostaining patterns on rat-brain sections to the first antiserum (see Results). Purified antibodies against neurogranin were obtained by affinity chromatography of purified serum IgG on neurogranin coupled to a glutaraldehyde-activated Trisacryl column.

Tissue and cell extracts. Tissues were freshly excised from rats killed by decapitation. The tissues $(0.5 \mathrm{gm} / \mathrm{ml})$ were homogenized in buffer A [100 mм Tris- $\mathrm{HCl}$ (pH, 7.4), 2 mм EDTA, 2 mм DTT, $100 \mathrm{~mm}$ $\mathrm{NaCl}$ and $1 \%$ Triton $\mathrm{X}-100$ ] using a Dounce homogenizer, and the extract was clarified by centrifugation. Perchloric acid was added to the supernatant (final concentration $2.5 \%$ ), which was immediately centrifuged for $15 \mathrm{~min}$ at $15000 \times \mathrm{g}$. The supernatant was then dialyzed overnight against $40 \mathrm{~mm}$ Tris- $\mathrm{HCl}(\mathrm{pH}, 6.9), 50 \mathrm{~mm} \mathrm{NaCl}$, and $2 \mathrm{~mm}$ DTT. Cortical neuronal cell cultures were obtained from fetal rats, as previously described (Gensburger et al., 1986). The cultures were rinsed 3 times with PBS. The cells were disrupted by brief sonication in buffer $A$ and processed in the same way as the tissue extract.

Immunoblotting. Tissue and cell extracts were electrophoresed in $0.1 \%$ : $12.5 \%$ SDS-polyacrylamide gels, then transferred electrophoretically to an Immobilon blotting membrane (Millipore). After transfer, the membrane was incubated $30 \mathrm{~min}$ with $3 \%$ gelatin in Tris-buffered saline (TBS) buffer [ $20 \mathrm{~mm}$ Tris- $\mathrm{HCl}(\mathrm{pH}, 7.5)$ and $0.5 \mathrm{M} \mathrm{NaCl})$. After being washed with TBS, the blotting membrane was incubated overnight at room temperature with primary antibodies diluted 1:1000 in TTBS buffer (TBS plus $0.05 \%$ Tween 20 ) containing $1 \%$ gelatin, followed by incubation for $2 \mathrm{hr}$ with alkaline phosphatase-conjugated goat antirabbit antibodies diluted with TTBS and $1 \%$ gelatin buffer. Immunoreactive bands were detected using 5-bromo-4-chloro-3-indolyl phosphate $(0.15 \mathrm{mg} / \mathrm{ml})$ and Nitro blue tetrazolium $(0.3 \mathrm{mg} / \mathrm{ml})$ in $40 \mathrm{~mm}$ sodium carbonate $(\mathrm{pH}, 9.8)$ and $5 \mathrm{mM} \mathrm{MgCl}_{2}$.

Tissue preparation. Male Sprague-Dawley rats (2-3 months old, $n=$ 6) were anesthetized by intraperitoneal injection of pentobarbital and perfused through the left ventricle with $50 \mathrm{ml} 0.9 \% \mathrm{NaCl}$, followed by 100 or $300 \mathrm{ml}$ of 1 of the 4 fixative solutions: (1) $4 \%$ paraformaldehyde in phosphate buffer $(\mathrm{pH}, 7.5)$ with or (2) without $0.2 \%$ glutaraldehyde, (3) $0.4 \%$ glutaraldehyde, or (4) $0.2 \%$ glutaraldehyde plus $0.1 \%$ picric acid. After fixation, the brain was dissected and immersed for 2 or 12 $\mathrm{hr}$ in the same fixative solution. The tissue was then either sectioned in different planes with a Vibratome $(30-80 \mu \mathrm{m})$ or dehydrated and embedded in paraffin to obtain $7-\mu \mathrm{m}$ sections.

Immunocytochemical staining. The best sections were chosen and used for immunocytochemical experiments. All steps were performed with gentle agitation of the sections. The sections were incubated in primary neurogranin antisera at dilutions $1: 100,1: 200,1: 500$, or 1:1000 in phosphate/ $\mathrm{NaCl}$ buffer plus $10 \%$ normal sheep serum for either 2 or $12 \mathrm{hr}$ at room temperature. The sections were washed for $1 \mathrm{hr}$ in 6-9 changes of phosphate/ $\mathrm{NaCl}$ buffer, then incubated $2-3 \mathrm{hr}$ with peroxidase-conjugated goat anti-rabbit IgG (diluted 1:200 in phosphate/ $\mathrm{NaCl}$ buffer plus $10 \%$ normal sheep serum). The last wash step employed 69 changes of phosphate/ $\mathrm{NaCl}$ buffer, and the peroxidase activity was developed for $10-15 \mathrm{~min}$ with $0.018 \% 4$-chloro-1-naphthol plus $0.03 \%$ hydrogen peroxide in phosphate $/ \mathrm{NaCl}$ buffer. Immunocytochemical controls were performed using normal rabbit serum or immunoserum preabsorbed with the purified protein $(0.1 \mathrm{mg} / \mathrm{ml})$.

To study the general distribution of neurogranin, we used different fixation protocols to eliminate the possibility of selective regional reduction of the antigenicity (see below), and 2 different rabbit antisera were used. In all cases, the staining pattern for neurogranin was highly

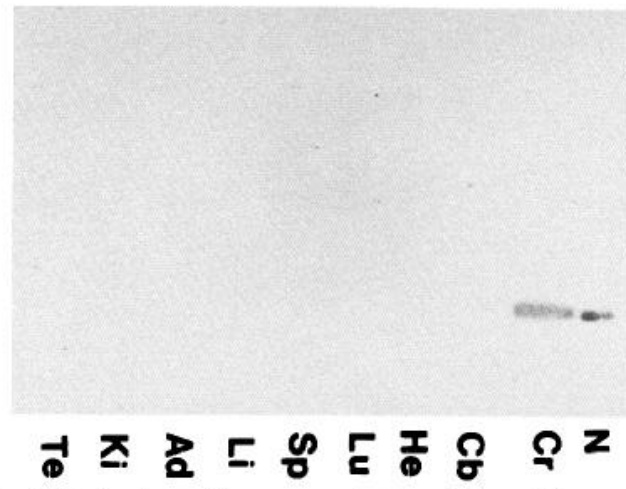

Figure 1. Distribution of neurogranin in adult rat tissues. Perchloric acid-treated extracts of adult rat tissues were resolved by SDS-PAGE and processed for immunoblotting as described in Materials and Methods. $N$, purified bovine-brain neurogranin monomer; $C r$, cerebrum; $C b$, cerebellum; $H e$, heart; $L u$, lung; $S p$, spleen; $L i$, liver; $A d$, adrenal gland; $K i$, kidney; Te, testis. The immunoreactive bands correspond to the neurogranin monomer. In each lane, the proteins loaded correspond to approximately $20 \mathrm{mg}$ tissue.

reproducible. The use of affinity-purified IgG against neurogranin gave a similar staining pattern to that of the crude antisera.

\section{Results}

\section{Tissue distribution and developmental expression of neurogranin}

The specificity of the polyclonal antibodies raised against pure neurogranin can be seen from transblot analysis of total and partially purified rat-brain extracts (Figs.1, 2). The major band detected in the total adult-rat-brain extracts migrated with the same apparent molecular weight as that of the purified bovine protein, indicating that neurogranin is not a proteolytic fragment of a larger molecule generated during purification. Although a sequence homology has been found between neurogranin and neuromodulin, polyclonal neurogranin antibodies did not crossreact with neuromodulin and vice versa (data not shown).

The tissue distribution of neurogranin in adult rat tissues was estimated by immunoblotting on homogenates treated with $2.5 \%$ perchloric acid as described in Materials and Methods. Neurogranin was found only in the cerebrum, not in the cerebellum or other tissues (Fig. 1).

The changes in the levels of neurogranin during brain postnatal development were analyzed by immunoblotting of crude rat-brain extracts (Fig. $2 A$ ). In the newborn rat brain, no neurogranin immunoreactivity could be detected after immunoblotting of brain extracts, suggesting that the synthesis of the protein occurs only after birth. The postnatal expression of neurogranin appeared to be very low up to 1 week of age, then a rapid increase was observed between 2 and 3 weeks. In addition, we did not find immunohistochemical labeling of brain structures in rats prior to the second postnatal week (results not shown).

We also investigated the expression of neurogranin in primary cell cultures derived from cerebral hemispheres of rats at different embryonic ages and harvested at different periods of time (Fig. $2 B$ ). The results were compared with those for neuromodulin and the microtubule-associated $\tau$ protein (Fig. $2 C, D$ ). In contrast to neuromodulin and $\tau$ protein, neurogranin was only present in advanced differentiated neurons (adult rats), but not in less mature cultured neurons.

To compare the abundance of neurogranin with that of neu- 


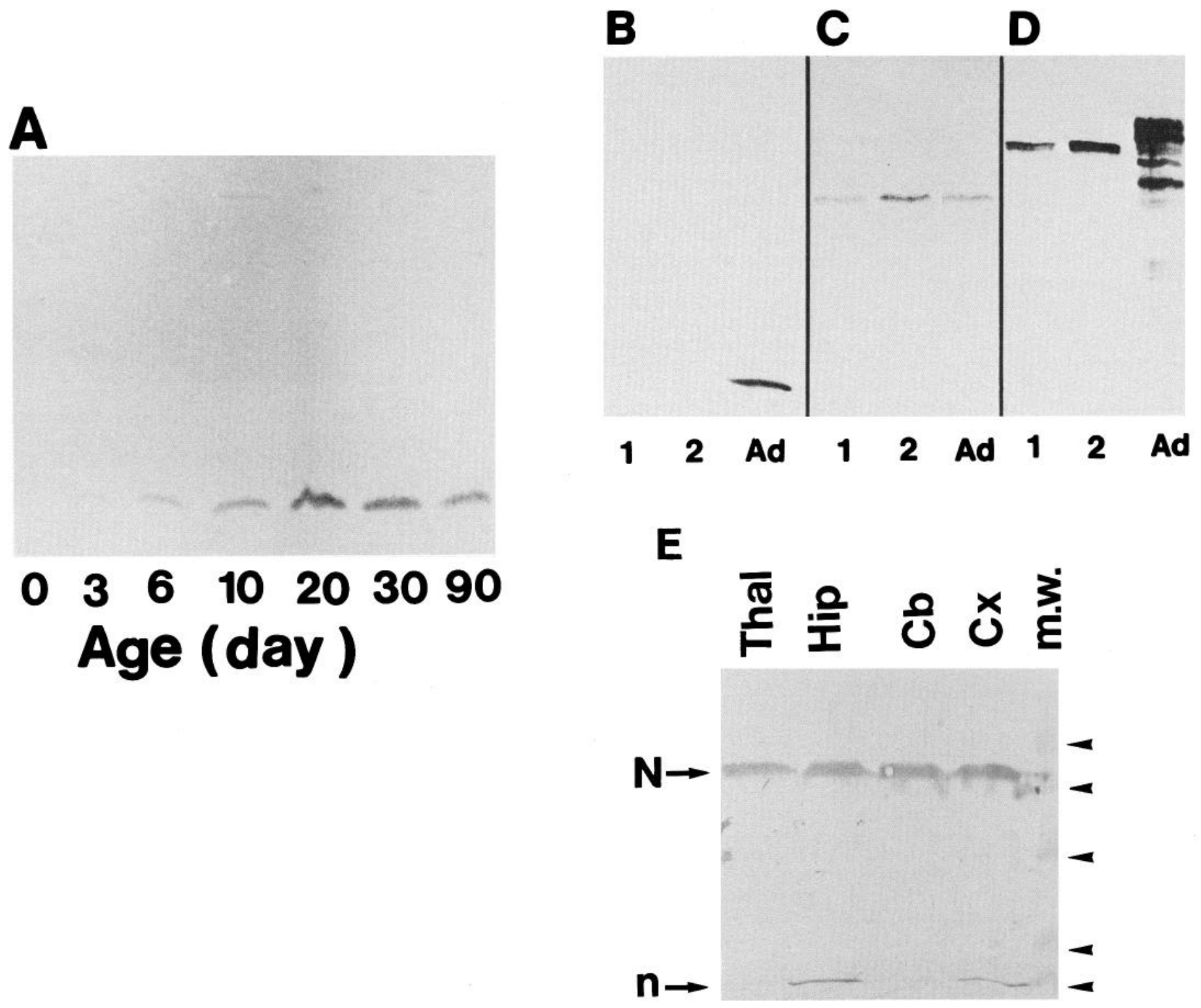

Figure 2. Developmental expression of neurogranin in rat brain tissue. $A$, Total brain extracts of newborn rats $(0)$ and from rats at different postnatal ages, as indicated, were analyzed by immunoblotting. The immunoreactive bands correspond to the neurogranin monomer. In each lane, the proteins loaded correspond to $10 \mathrm{mg}$ tissue. $B-D$, Comparison of the expression of neurogranin $(B)$, neuromodulin $(C)$, and $\tau$ proteins $(D)$ in primary cortical neuronal cell cultures derived from brains of rats at embryonic day 14 (E14) harvested after $7 \mathrm{~d}$ (lane 1 ) and E17 harvested after $4 \mathrm{~d}$ (lane 2). Perchloric acid-treated cell extracts were analyzed by immunoblotting using antibodies (1:1000 dilution) against neurogranin (B), neuromodulin $(C)$, and $\tau$ proteins $(D)$. $A d$, adult rat brain extract. $E$, Comparison of the neurogranin and neuromodulin antigens in Triton $\mathrm{X}-100$ solubilized extracts of rat cortex $(C X)$, cerebellum $(C b)$, hippocampus $(\mathrm{Hip})$, and thalamus (Thal) by Western blots. In each lane, the proteins loaded correspond approximately to $2.5 \mathrm{mg}$ tissue. The proteins were first separated by SDS-polyacrylamide (0.1\%:12.5\%) gel electrophoresis, then transferred electrophoretically to an Immobilon blotting membrane, and the membrane was incubated with a mixture of neurogranin and neuromodulin antibodies (1:200 dilution) for $2 \mathrm{hr}$. Arrowheads indicate position of colored molecular-weight markers $(m . w$.): $14.3 \mathrm{kDa}, 21.5 \mathrm{kDa}, 30$ $\mathrm{kDa}, 46 \mathrm{kDa}$, and $68 \mathrm{kDa}$. Arrows indicate position of neuromodulin $(N)$ and neurogranin $(n)$.

romodulin in different regions of the adult rat brain, we analyzed the presence of these 2 proteins on the same Western blot of Triton X-100-solubilized extracts of the cortex, thalamus, hippocampus, and cerebellum (Fig. $2 E$ ). Neuromodulin immunoreactivity was found abundant in the 4 extracts, while neurogranin appeared as minor immunoreactive bands only in cortical and hippocampal extracts. These data indicate that neurogranin is, therefore, present at a much lower concentration than neuromodulin in the adult rat brain.

\section{Regional distribution of neurogranin in the adult rat brain}

Figure $3 A$ shows typical immunocytochemical staining of neurogranin in a parasagittal section of an adult rat brain. Figure $3 B$ schematically depicts the relative intensity of neurogranin immunoreactivity in some brain structures. The highest immunoreactivity was found in certain layers of the hippocampal formation and the neocortex. Medium staining densities were found in the striatum, colliculi, pyriform cortex, olfactory tu- 


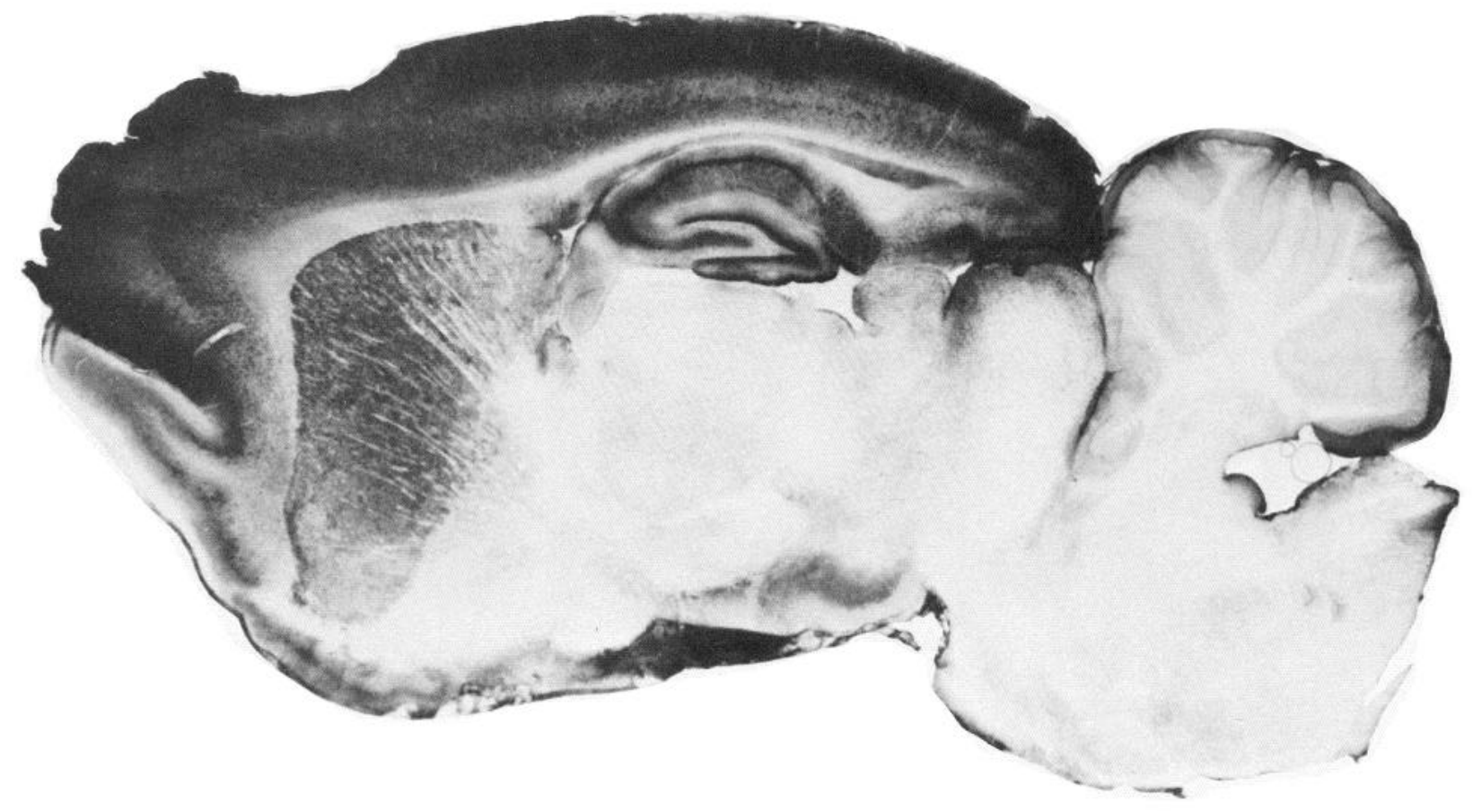

B

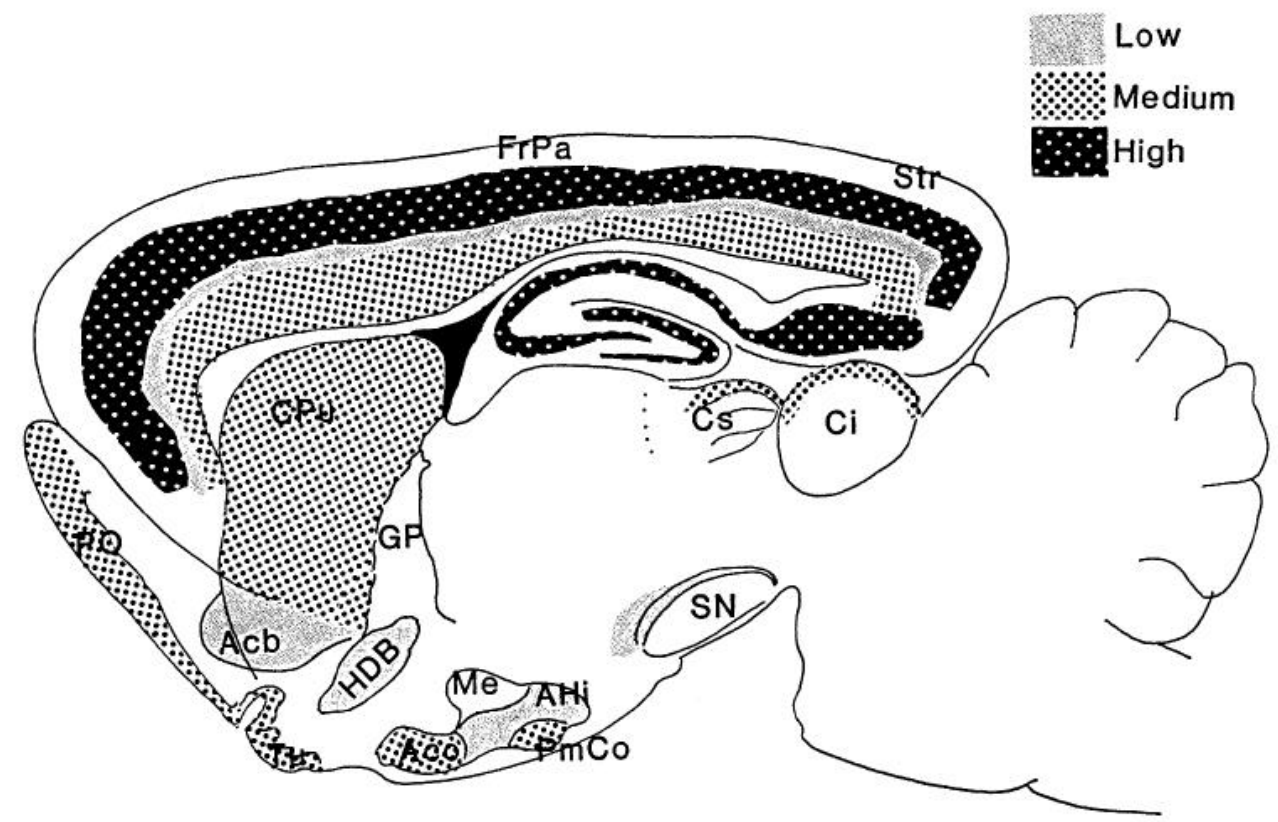

Figure 3. Neurograninlike immunoreactivity in parasagittal sections of adult rat brain $(80 \mu \mathrm{m})$. A, The brain of a 2 -month-old rat was fixed in $4 \%$ paraformaldehyde and $0.1 \%$ glutaraldehyde. Slices were incubated with 1:100 dilution of rabbit polyclonal antibodies against neurogranin for $12 \mathrm{hr}$ at room temperature, and the immunoreactivity was revealed by the peroxidase method as described in Materials and Methods. $B$, Semiquantitative distribution of neurogranin; high, medium, and low immunostaining densities in various areas are indicated. See Appendix for abbreviations.

bercle, and some amygdala nuclei. Neurogranin immunoreactivity was almost completely absent in the thalamus, cerebellum, brain stem, and spinal cord. The dark appearance of the outer surface of the cerebellum and of the middle part of the corpus callosum sandwiched between the hippocampus and the overlying cortex seen in Figure $3 A$ is not immunochemical staining. This is a photographic artifact due to the brightness of the flash light on the sides of the slice. 

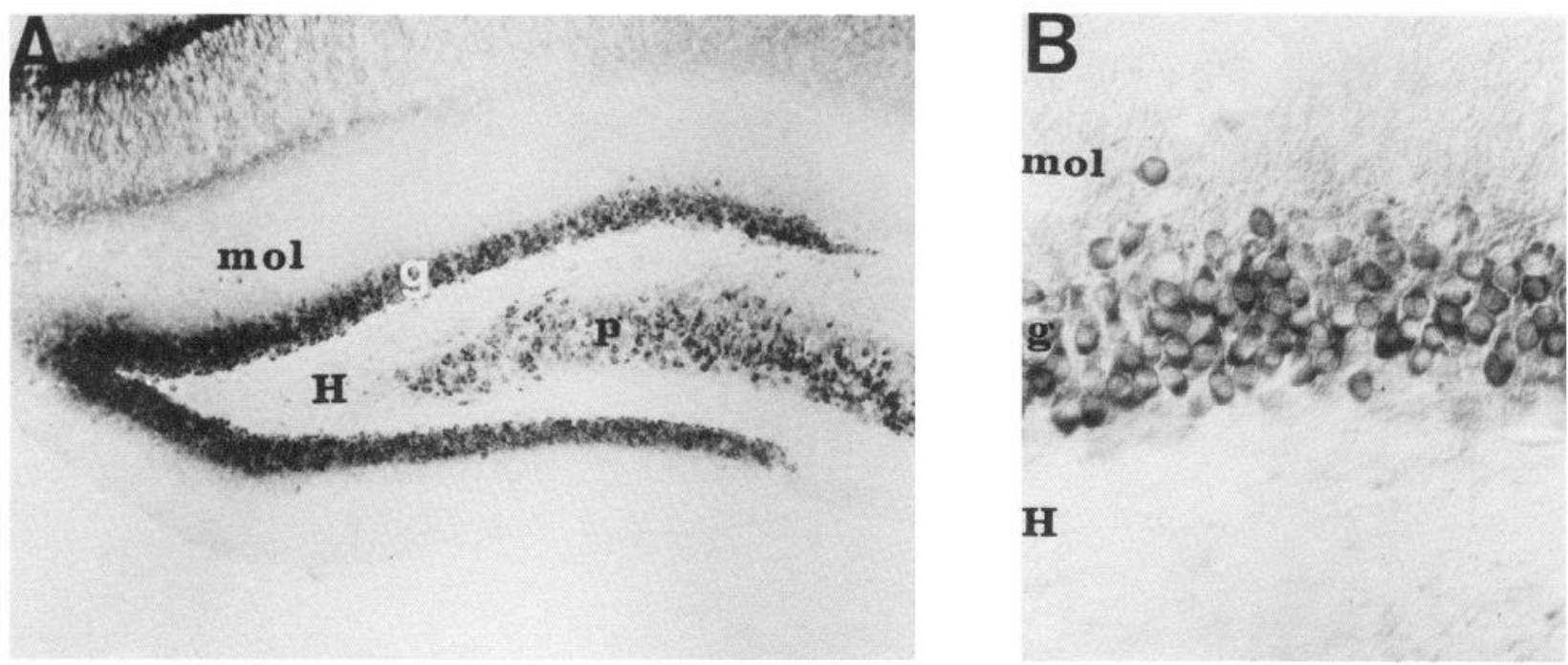

\section{$\mathbf{H}$}
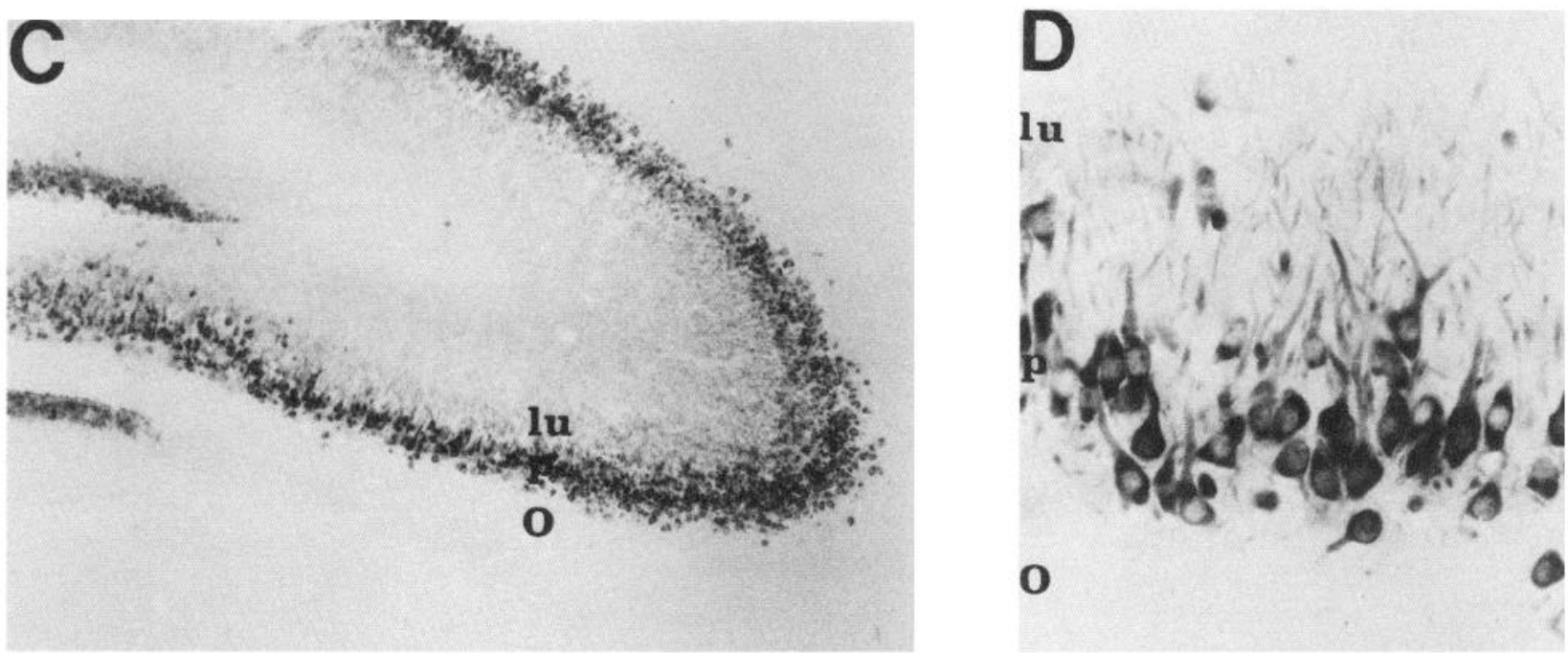

$\mathbf{0}$
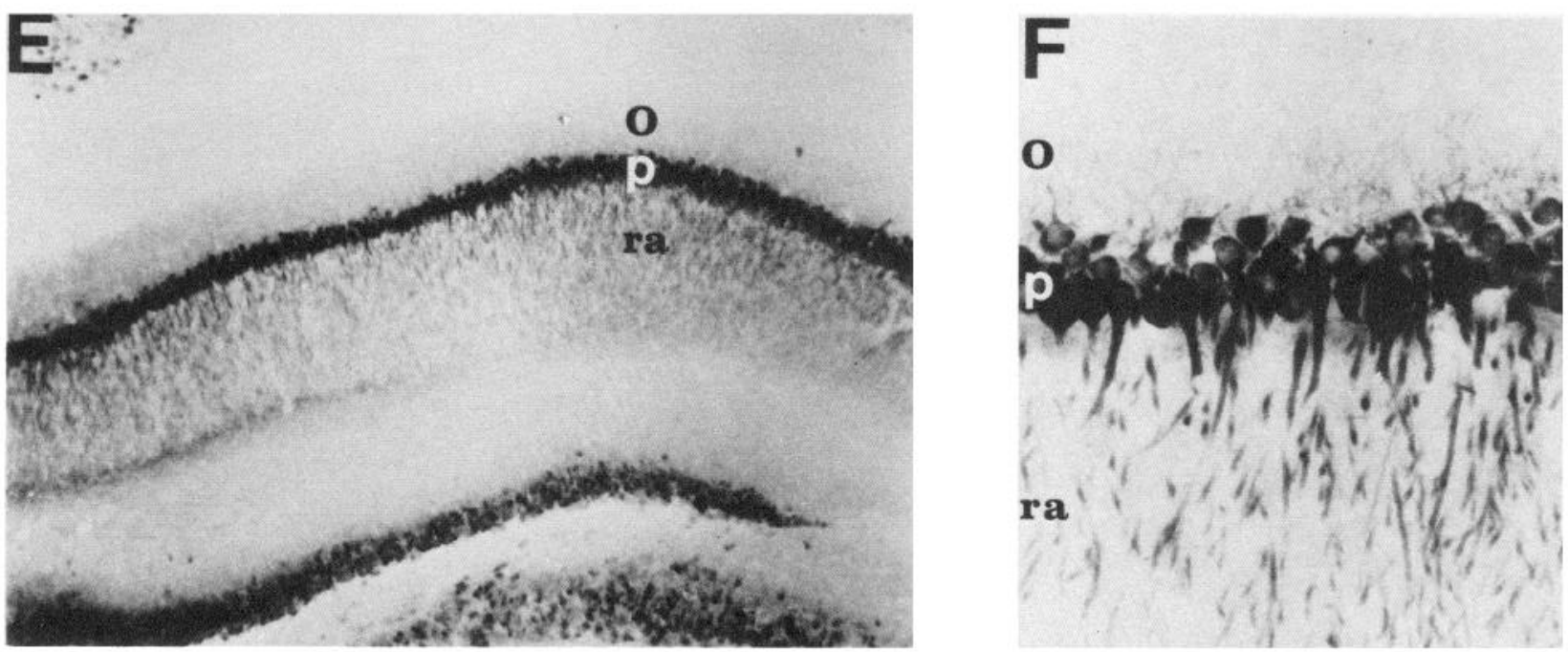

Figure 4. Distribution of neurogranin in coronal $(7-\mu \mathrm{m})$ section of hippocampal formation. $A$ and $B$, In the fascia dentata, neurogranin immunoreactivity is found almost exclusively in the granular cells; the soma appears well stained, whereas the dendrites appear poorly immunoreactive. The interneurons (located in the hilus) are rarely immunoreactive. $C$ and $D$, Distribution of neurogranin in the CA 3 field; pyramidal cells show high density of immunostaining in the soma and the apical dendrites (in the stratum lucidum), whereas the basal dendrites are devoid of immu- 
Observations at higher magnification indicated that the staining was restricted to neurons in all neurogranin-positive regions. No staining of glial cells could be observed. The staining was predominantly found in the perikarya and the dendrites of pyramidal neurons; axons were not labeled. The nuclei of the neurons appear rarely immunoreactive, except in the cerebral cortex (see Fig. 5C).

The same immunocytochemical staining pattern was observed with serum dilutions from $1: 100$ up to $1: 1000$ and with affinity-purified antibodies. Only the intensity of the staining decreased with the higher serum dilutions. The specificity of the immunostaining was further confirmed by preadsorption of the anti-neurogranin serum with the purified protein. The immunostaining was totally inhibited when the serum was preincubated for $4 \mathrm{hr}$ with purified neurogranin $(0.1 \mathrm{mg} / \mathrm{ml}$; data not shown but provided to referees for examination).

Figures 4-8 illustrate in detail the distribution of neurogranin in the various structures and the localization at the cellular level.

In the hippocmapal formation (Fig. 4), most of the pyramidal neurons of Ammon's horn and the subiculum and the granular cells of the fascia dentata were conspicuously stained; only a few putative interneurons in the hilus (Fig. $4 A$ ) and the stratum oriens of Ammon's horn (Fig. $4 C, E$ ) showed a positive immunostaining. As shown in Figure $4 B, D$, and $F$, neurogranin immunostaining clearly depicted the perikarya of both pyramidal and granular cells, whereas only the apical dendrite of pyramidal cells showed dense immunostaining; the basal dendrites of pyramidal cells and the dendritic arborization of granular cells showed fair immunostaining. There were no signs of staining in axons; that is, in the lucidum layer, occupied by the mossy fibers, only dendrites appeared stained. The alveus, occupied by the axons of pyramidal cells, also appeared devoid of immunodeposits.

The cerebral neocortex (Figs. 3, 5, 6), with the hippocampal complex, showed the highest density of immunolabeling. The entire cortex was well stained, including the pyriform (Fig. 6B), entorhinal (Fig. 6D), cingular, temporal, frontoparietal (Fig. $5 A, C$ ), and striatal cortices (Fig. $5 B, D$ ), with a slight predominance in the striatal and frontoparietal cortices. The immunolabeling has a characteristic laminar pattern, with the highest neuronal immunostaining in layers II-IV and VIa (Fig. $5 A, B, D$ ). In these layers, the perikarya and the dendritic trees, particularly the long apical dendrites of the pyramidal cells, appeared intensely stained. Occasionally, the nucleus of pyramidal and nonpyramidal neurons were also stained (Fig. $5 \mathrm{C}$ ). In layer $\mathrm{V}$, only a few large pyramidal cells appeared slightly immunolabeled. The immunoreaction clearly stained the terminal arborization of pyramidal dendrites in layer $\mathrm{I}$.

In the amygdala (Fig. 6), most of the different nuclei appeared stained by the neurogranin antibodies; only the medial nuclei was devoid of cellular staining. The strongest immunostaining was found in the basolateral, anterior cortical, and central amygdaloid nuclei; in contrast, the basomedial, intercalated, and amygdalohippocampal areas were moderately stained.

The basal ganglia (Figs. 3, 7) also appeared heterogeneously stained. The highest density of immunolabeling was found in the soma of neurons of the caudate putamen (Fig. 7). The claus- trum and the accumbens were moderately labeled, whereas the globus pallidus was not immunostained (Fig. 3).

The septal region was weakly stained; only a few neurons in the latero-dorsal pathways showed a slight immunolabeling.

The diencephalon (Fig. 3) showed very poor immunolabeling. Low densities of immunostaining were found in the habenula and in a few neurons of the zona incerta, dorsolateral thalamic nucleus, subthalamic area, peripeduncular nucleus (Figs. 3, 8B), and anterior hypothalamic area.

The brain stem presented a clear immunolabeling only in the superior and inferior colliculus (Fig. 3); this was, however, limited to the more superficial layers (superficial gray layer). As shown in Figures 3 and $8 A$, the cerebellum was devoid of immunolabeling, in both the cerebellar cortex and the cerebellar nuclei.

\section{Discussion}

Identifying the key substrates is a crucial step for the understanding of signal-transduction mechanisms through PKC. We have previously identified neurogranin (p17) as an in vitro substrate for PKC (Baudier et al., 1989). Phosphorylation studies of neurogranin in intact hippocampal slices have revealed that it is a phosphoprotein in vivo and that PKC activators, such as phorbol ester, stimulate neurogranin phosphorylation. Although the primary structure of neurogranin is unique, protein sequencing revealed a consensus amino acid sequence between neurogranin and neuromodulin (GAP43), corresponding to the PKC phosphorylation site and calmodulin-binding domain ( $\mathrm{J}$. Baudier, J. C. Deloulme, H. Mattes, and M. Sensenbrenner, unpublished observations). Here, we confirmed that neurogranin is distinct from neuromodulin by its late developmental expression, its dendritic localization in neuronal cells, and its low abundance in the adult rat brain.

The distribution of neurogranin in the adult rat brain parallels in many aspects that of the PKC isozymes (Brandt et al., 1987; Huang et al., 1988; Saito et al., 1988). Neurogranin is found in anatomical areas of the rat telencephalon, where PKC is also highly concentrated, notably in the cortex and hippocampus. However, neurogranin is absent in zones such as the substantia nigra and the cerebellum, where PKC is also very abundant (Huang et al., 1988).

Studies on the distribution of PKC isozymes showed a distinct cellular localization of the different isozyme types; it has, therefore, been suggested that each isozyme is involved in a specialized function (Huang et al., 1988). PKC substrates are the first molecular support of the transduction of the PKC activation signal. Therefore, one might expect that each PKC isozyme is also characterized by its own substrate specificity within the same cells.

Several observations suggest a preferential colocalization of the PKC type I isozyme and neurogranin: neurogranin and type I isozyme are found in nervous tissues but not in other organs, they are not detected in early postnatal rats, and the expression of both proteins increases gradually to reach a maximal adult level around postnatal day 30 (Hashimoto et al., 1988; Yoshida et al., 1988). In contrast, type II and III PKC isozymes are expressed in various organs, as well as in nervous tissues. In the

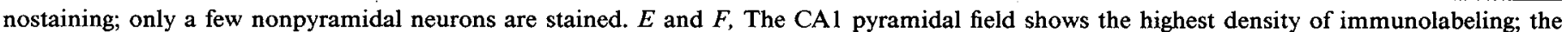

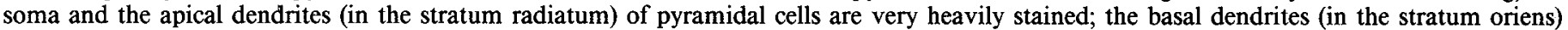
appear scarcely stained. $A, C$, and $E: 25 \times ; B, D$, and $F: 125 \times$. See Appendix for abbreviations. 

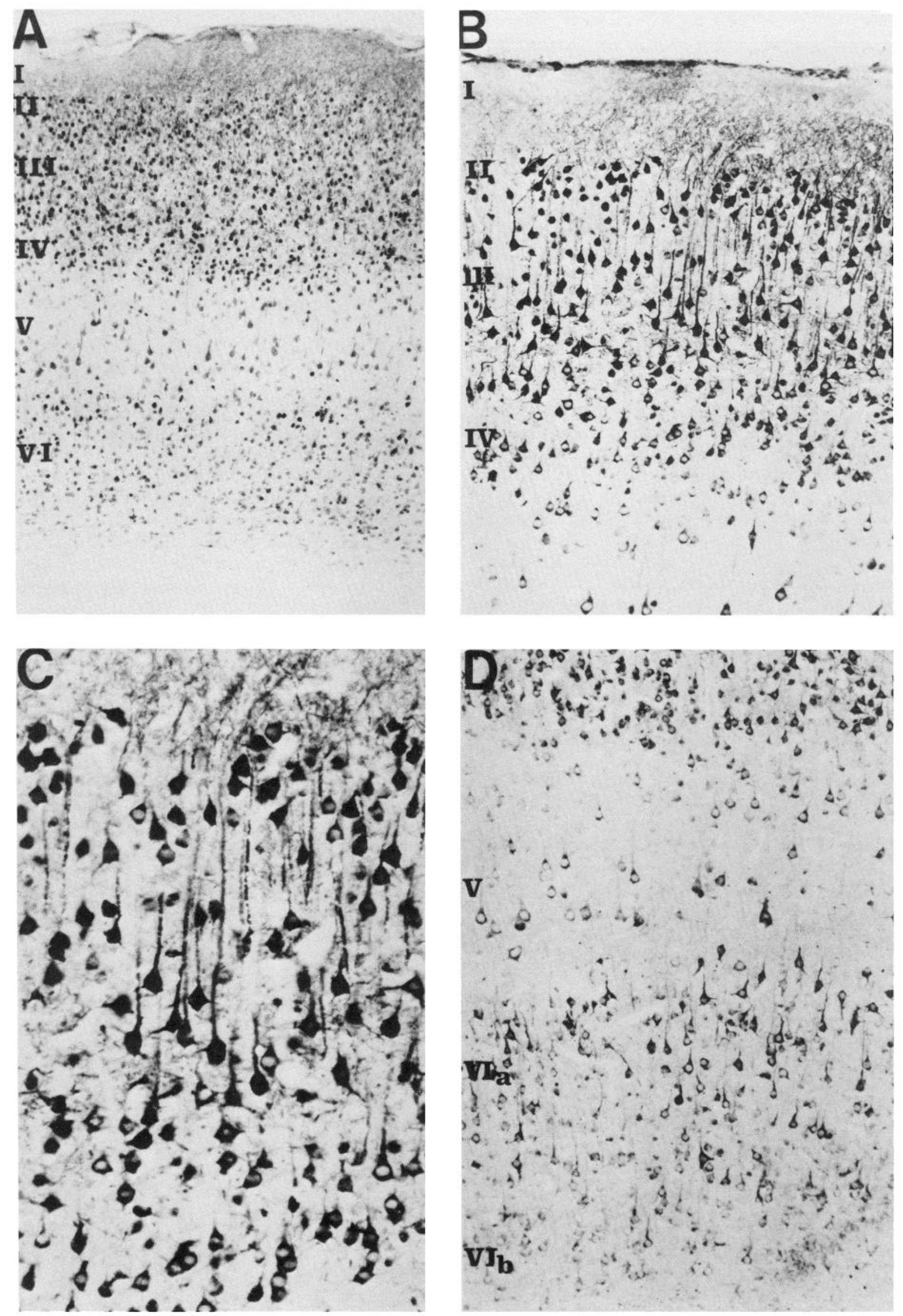

Figure 5. Micrographs showing the distribution of neurogranin in rat neocortex (7- $\mu \mathrm{m}$ section). $A$, Coronal section of the frontal cortex $(25 \times)$. $B$ and $D$, Coronal section of the striatal cortex $(62.5 \times)$. C, Horizontal section of the frontoparietal cortex $(125 \times)$. Note the high immunostaining of the cellular layers II-IV; the soma and the apical and basal dendrites of pyramidal cells are densely stained; some neurons show a clear staining of their nucleus. 

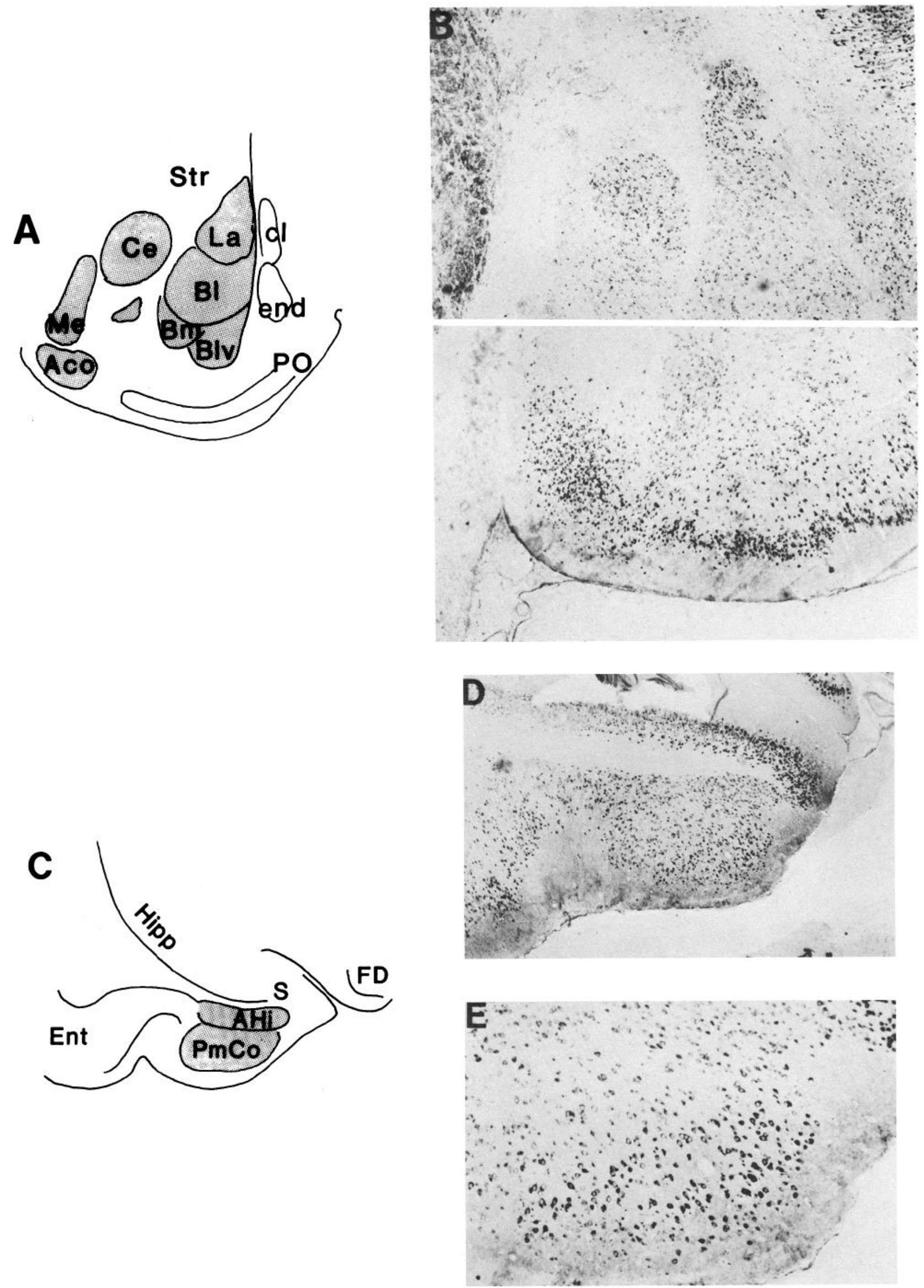

Figure 6. Diagrams $(A, C)$ and coronal sections $(B, D, E)$ showing distribution of neurogranin immunoreactivity at level of amygdala. The strongest labeling is found in the basolateral, cortical, and amygdalocortical nuclei. $B$ and $D$ also show the presence of immunostaining in the entorhinal and primitive olfactory cortices. $B$ and $D, 25 \times ; E, 62.5 \times$. See Appendix for abbreviations. 

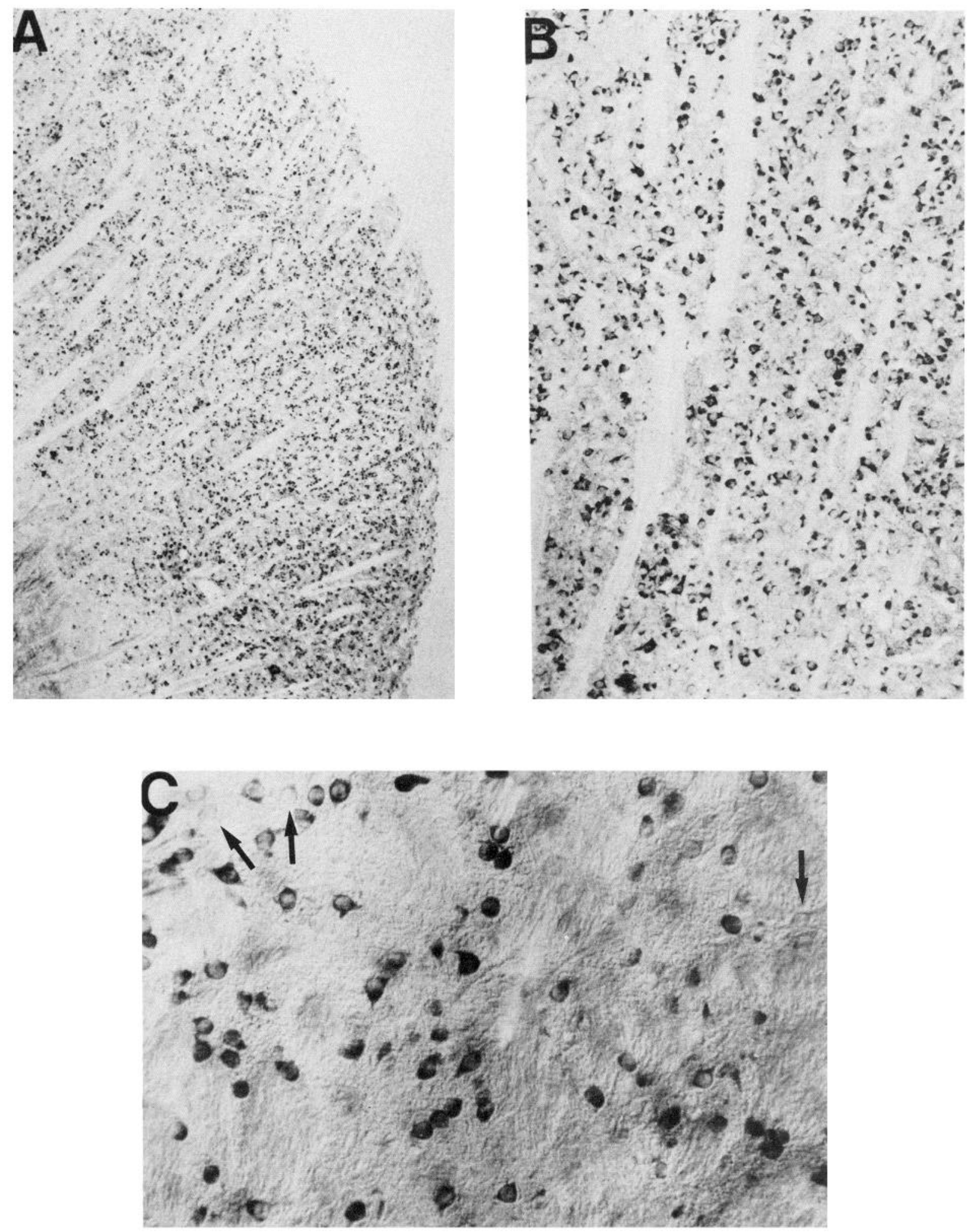

Figure 7. Neurogranin immunoreactivity in caudate putamen. Immunostaining is found exclusively in the soma of neurons; the dendrites and axons are devoid of immunodeposits. Arrows indicate a few nonimmunoreactive neurons. $A, 25 \times ; B, 62.5 \times ; C, 125 \times$.

brain, type II and type III PKC are already present at birth, increase rapidly, and reach a plateau level at 2 weeks. Furthermore, in adult-rat-brain sections, neurogranin has a similar immunostaining pattern to type I PKC (Nishizuka, 1988; Saito et al., 1988), whereas it differs from the distribution of type II and
III PKC (Huang et al., 1988; Hosoda et al., 1989; Saito et al., 1989). Moreover, electron microscopic studies on the cellular localization of $\beta_{1 \mathrm{II}}$ PKC (type II) suggested a preferential association of these subspecies with the Golgi complex (Saito et al., 1989). Finally, Brandt et al. (1987), by contrasting the locali- 

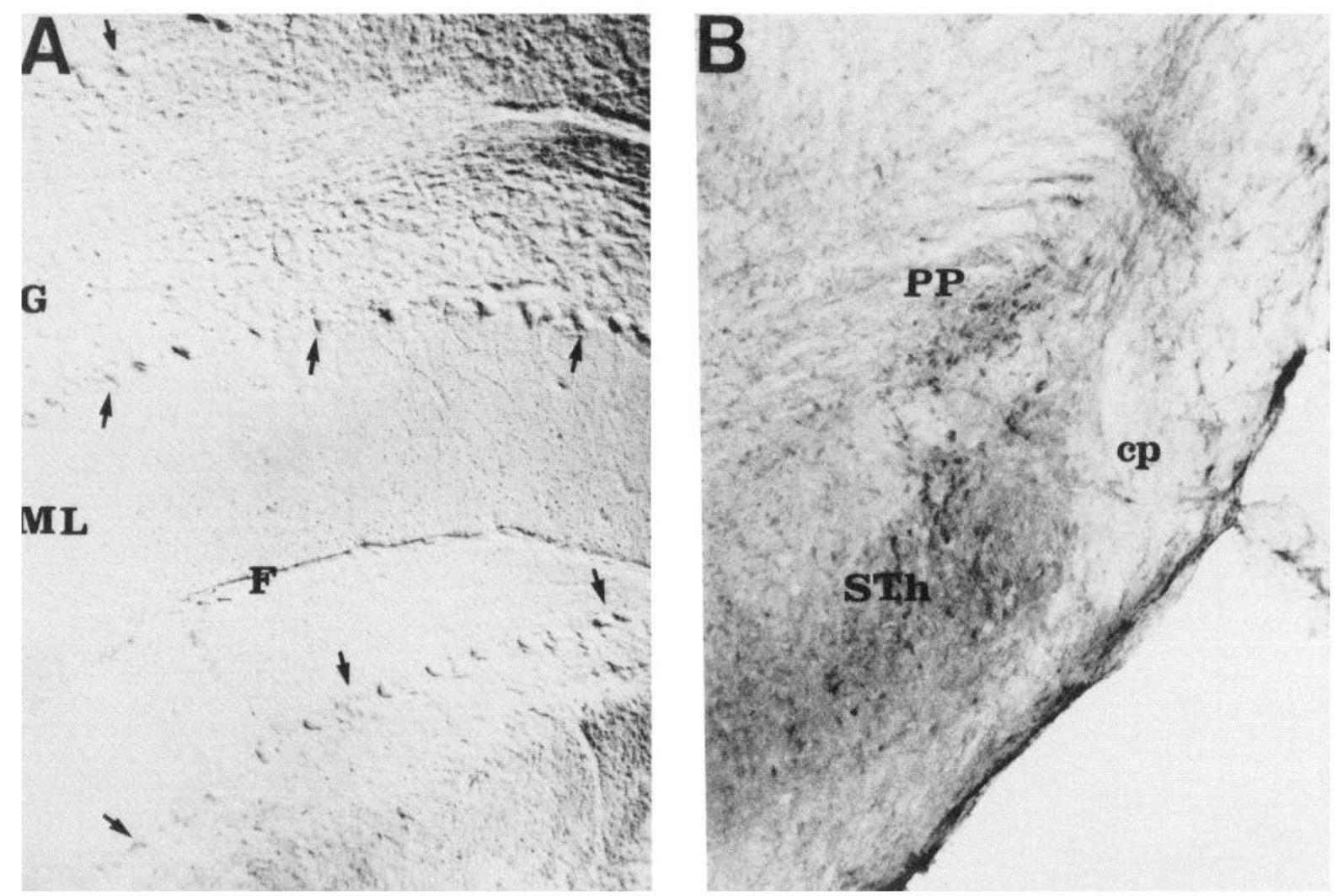

Figure 8. A, Cerebellum appears devoid of neurogranin immunostaining. Arrows point to the Purkinje cell layer $(125 \times)$. B, In the diencephalon, only a few neurons in the peripeduncular nucleus $(P P)$ and the subthalamic field $(S T h)$ appeared immunostained $(62.5 \times)$.

zation of PKC proteins, PKC mRNA, and phorbol ester bindings, have suggested that PKC-I proteins are located postsynaptically (as is neurogranin), whereas PKC-II and PKC-III proteins are located presynaptically in the cerebellum and the striatonigral fibers. Recently, Huang (1989) reported that, in the cerebellum, even though PKC-I and PKC-III colocalize in Purkinje cells, only PKC-I, not PKC-III, is present in the dendrites of these cells, suggesting a function for PKC-I in postsynaptic signal transduction (Huang, 1989). However, several studies suggested a preferential postsynaptic localization of all $3 \mathrm{PKC}$ isoforms in the hippocampus and neocortex (Worley et al., 1986; Huang et al., 1988; Saito et al., 1988, 1989). Work is in progress to analyze in vitro the kinetics and other parameters of neurogranin phosphorylation by the different PKC isozymes, which may help to understand the substrate specificity of each isoform and the physiological functions of these enzymes.

It has been shown that activation of PKC can mimic the biophysical effects of associative learning on neurons, and that associative memory induces activation and translocation of the PKC from the cell soma to the dendrites of the CA1 pyramidal cells of the hippocampus (Olds et al., 1989), where endogenous substrates will support the transduction of the PKC activation signal. PKC activation is also necessary for the maintenance of long-term potentiation (LTP) (see Linden and Routtenberg, 1989, for review), a synaptic model of memory produced by a brief train of high-frequency electrical stimulation (Bliss and Lomo, 1973) or by phorbol esters (Malenka et al., 1986; Aniksztejn et al., 1987). Moreover, in the CA1 region of the hippocampus, intracellular delivery of PKC inhibitors blocks LTP induction but not its expression, suggesting that postsynaptic PKC is necessary for the induction of LTP (Malinow et al., 1989). To our knowledge, neurogranin is the first postsynaptic PKC substrate identified to date that is specific to soma and dendrites and is abundantly present in areas of the adult rat brain that are capable of long-lasting enhancement of synaptic transmission, notably, the hippocampus and neocortex (Iriki et al., 1989). Further studies on a possible role of neurogranin in the transduction of the PKC activation signal in synaptic plasticity have to be considered.

It is also significant that neuromodulin (also called F1, B50, and GAP43), which is found highly concentrated in neuropil layers (i.e., the stratum oriens and stratum radiatum of the CA1 area and the molecular layer of the fascia dentata), seems to be located presynaptically (Snipes et al., 1987; MacGuire et al., 1988). Activation of a presynaptic protein kinase and phosphorylation of neuromodulin could also be necessary for the maintenance of LTP (Linden and Routtenberg, 1989; Malinow et al., 1989); nevertheless, the type of PKC involved is presently unknown, because, at least in the CA1 area, the defined PKC isozymes are all postsynaptically located (Worley et al., 1986; Hvang et al., 1988; Saito et al., 1988, 1989).

Finally, in addition to its possible functional importance, the neurogranin antigen may also serve as a specific marker of neuronal cell types, particularly suitable in the hippocampus, where it is found almost exclusively in the pyramidal and granular cells, but not in interneurons.

\section{Appendix}

$\begin{array}{ll}\text { Acb } & \text { accumbens nucleus } \\ \text { Aco } & \text { anterior cortical amygdaloid nucleus } \\ \text { AHi } & \text { amygdalohippocampal nucleus } \\ \text { Bl } & \text { basolateral amygdaloid nucleus } \\ \text { Blv } & \text { basolateral amygdaloid nucleus, ventral }\end{array}$




$\begin{array}{ll}\text { Bm } & \text { basomedial amygdaloid nucleus } \\ \text { Ce } & \text { central amygdaloid nucleus } \\ \text { Ci } & \text { inferior colliculus } \\ \text { cl } & \text { claustrum } \\ \text { cp } & \text { cerebral peduncle } \\ \text { CPu } & \text { caudate putamen } \\ \text { Cs } & \text { superior colliculus } \\ \text { end } & \text { endopiriform nucleus } \\ \text { Ent } & \text { entorhinal cortex } \\ \text { F } & \text { primary fissure } \\ \text { FD } & \text { fascia dentata } \\ \text { FrPa } & \text { frontoparietal cortex } \\ \text { G and g } & \text { granular layer } \\ \text { GP } & \text { globus pallidus } \\ \text { H } & \text { hilus } \\ \text { HDB } & \text { horizontal limb of the diagonal band } \\ \text { Hipp } & \text { hippocampus } \\ \text { La } & \text { lateral amygdaloid nucleus } \\ \text { lu } & \text { stratum lucidum } \\ \text { Me } & \text { medial amygdaloid nucleus } \\ \text { ML } & \text { molecular layer } \\ \text { mol } & \text { molecular layer of fascia dentata } \\ \text { o } & \text { stratum oriens } \\ \text { p } & \text { pyramidal layer } \\ \text { PmCo } & \text { posteromedial cortical amygdaloid nucleus } \\ \text { PO } & \text { pyriform cortex } \\ \text { PP } & \text { peripeduncular nucleus } \\ \text { ra } & \text { stratum radiatum } \\ \text { S } & \text { subiculum } \\ \text { SN } & \text { substantia nigra } \\ \text { STh } & \text { subthalamic field } \\ \text { Str } & \text { striatal cortex } \\ \text { Tu } & \text { olfactory tubercle } \\ & \end{array}$

\section{References}

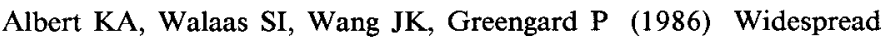
occurrence of "P87 kDa," a major specific substrate for protein kinase C. Proc Natl Acad Sci USA 83:2822-2826.

Alexander KA, Wakim BT, Doyle GS, Walsh KA, Storm DR (1988) Identification and characterization of the calmodulin-binding domain of neuromodulin, a neurospecific calmodulin-binding protein. J Biol Chem 263:7544-7549.

Aniksztejn L, Roisin MP, Gozlan H, Ben-Ari Y (1987) Long-lasting potentiation produced by a phorbol ester in the hippocampus of the anaesthetized rat is not associated with a persistent enhanced release of excitatory amino acids. Neurosci Lett 81:291-295.

Baudier J, I ee SH, Cole RD (1987) Separation of the different microtubule-associated tau protein species from bovine brain and their mode II phosphorylation by the $\mathrm{Ca}^{2+}$ phospholipid-dependent protein kinase C. J Biol Chem 362:17584-17590.

Baudier J, Bronner C, Kligman D, Cole RD (1989) Protein kinase C substrates from bovine brain: purification and characterization of neuromodulin, a neuron-specific calmodulin-binding protein. J Biol Chem 264:1824-1828.

Bliss TVP, Lomo T (1973) Long lasting potentiation of synaptic transmission in the dentate area of the anesthetized rabbit following stimulation of the perforant path. J Physiol (Lond) 232:331-356.

Brandt SJ, Niedel JE, Bell RM, Young SW III (1987) Distinct patterns of expression of different protein kinase $\mathrm{C}$ mRNAs in rat tisues. Cell 49:57-63.

Cimler MB, Giebelhaus DH, Wakim BT, Storm DR, Moon RT (1987) Characterization of murine cDNAs encoding p57, a neural-specific calmodulin-binding protein. J Biol Chem 262:12158-12163.

Coussens L, Parker PJ, Rhee L, Yang-Feng TL, Chen E, Waterfield MD, Francke U, Ullrich A (1986) Multiple, distinct forms of bovine and human protein kinase $C$ suggest diversity in cellular signaling pathways. Science 233:859-866.

Gensburger C, Labourdette G, Sensenbrenner M (1986) Influence of meningeal cells on the proliferation and maturation of rat neuroblasts in culture. Exp Brain Res 63:321-330.

Hashimoto T, Ase K, Sawamura S, Kikkawa U, Saito N, Tanaka C, Nishizuka Y (1988) Postnatal development of a brain-specific subspecies of protein kinase $C$ in rat. J Neurosci 8:1678-1683.

Hosoda K, Saito N, Kose A, Ito A, Tsujino T, Ogita K, Kikkawa U, Ono Y, Igarashi K, Nishizuka Y, Tanaka C (1989) Immunocytochemical localization of the $\beta_{1}$ subspecies of protein kinase $C$ in rat brain. Proc Natl Acad Sci USA 86:1393-1397.

Huang KP (1989) The mechanism of protein kinase $C$ activation. Trends Neurosci 12:425-432.

Huang KP, Nakabayashi H, Huang FL (1986) Isozymic forms of rat brain $\mathrm{Ca}^{2+}$-activated and phospholipid-dependent protein kinase. Proc Natl Acad Sci USA 83:8535-8539.

Huang FL, Yoshida Y, Nakabayashi H, Huang KP (1987) Differential distribution of protein kinase $\mathrm{C}$ isozymes in the various regions of brain. J Biol Chem 262:15714-15720.

Huang FL, Yoshida Y, Nakabayashi H, Young SW, Huang KP (1988) Immunocytochemical localization of protein kinase $\mathrm{C}$ isozymes in rat brain. J Neurosci 8:4734-4744.

Iriki A, Pavlides C, Keller A, Asanuma H (1989) Long-term potentiation in the motor cortex. Science 245:1385-1387.

LaBate ME, Skene JHP (1989) Selective conservation of GAP 43 structure in vertebrate evolution. Neuron 3:299-310.

Linden DJ, Routtenberg A (1989) The role of protein kinase C in long-term potentiation: a testable model. Brain Res Rev 14:279-296.

MacGuire CB, Snipes GJ, Norden JJ (1988) Light-microscopic immunolocalization of the growth- and plasticity-associated protein GAP43 in the developing rat brain. Dev Brain Res 41:277-291.

Malenka RC, Madison DV, Nicoll RA 91986) Potentiation of synaptic transmission in the hippocampus by phorbol esters. Nature 321:175177.

Malinow R, Schulman H, Tsien RW (1989) Inhibition of postsynaptic PKC or CaMKII blocks induction but not expression of LTP. Science 245:862-865.

Masure RH, Alexander KH, Wakim B, Storm DR (1986) Physicochemical and hydrodynamic characterization of $\mathrm{p}-57$, a neurospecific calmodulin binding protein. Biochemistry 25:7553-7560.

Nishizuka Y (1988) The molecular heterogeneity of protein kinase C and its implications for cellular regulation. Nature 334:661-665.

Olds JL, Anderson ML, McPhie DL, Staten LD, Alkon DL (1989) Imaging of memory-specific changes in the distribution of protein kinase $C$ in the hippocampus. Science 245:866-869.

Saito N, Kikkawa U, Nishizuka Y, Tanaka C (1988) Distribution of protein C-like immunoreactive neurons in rat brain. J Neurosci 8: 369-382.

Saito N, Kose A, Ito A, Hosada K, Mori M, Hirata M, Ogita K, Kikkawa U, Ono Y, Igarashi K, Nishizuka Y (1989) Immunocytochemical localization of $\beta_{\text {I }}$ subspecies of protein kinase $C$ in rat brain. Proc Natl Acad Sci USA 86:3409-3413.

Snipes GJ, Chan SY, McGuire CB, Costello BR, Norden JJ, Freeman JA, Routtenberg A (1987) Evidence for the coidentification of GAP43 , a growth-associated protein, and $\mathrm{F} 1$, a plasticity-associated protein. J Neurosci 7:4066-4075.

Stumpo DJ, Graff JM, Albert KA, Greengard P, Blackshear PJ (1989) Molecular cloning, characterization, and expression of a cDNA encoding the $80-$ to $-87-\mathrm{kDa}$ myristoylated alanine-rich $\mathrm{C}$ kinase substrate; a major cellular substrate for protein kinase C. Proc Natl Acad Sci USA 86:4012-4016.

Van Hoff COM, De Grann PN, Oestreicher AB, Gispen WH (1988) B50 phosphorylation and polyphosphoinositide metabolism in nerve growth cone membranes. J Neurosci 8:1789-1795.

Worley PF, Baraban JM, Snyder SH (1986) Heterogeneous localization of protein kinase $\mathrm{C}$ in rat brain: autoradiographic analysis of phorbol ester receptor binding. J Neurosci 6:199-207.

Yoshida Y, Huang FL, Nakabayashi H, Huang KP (1988) Tissue distribution and developmental expression of protein kinase $\mathrm{C}$ isozymes. J Biol Chem 263:9868-9873. 